\title{
Perancangan Sistem Manajemen Validasi Document Security Menggunakan QR Code Berbasis Website
}

\author{
Yoshua Kenny Nugroho', Magdalena Ariance Ineke Pakereng ${ }^{2}$ \\ ${ }^{1,2}$ Fakultas Teknologi Informasi, Universitas Kristen Satya Wacana \\ Jl. Dr. O. Hamidjojo, Salatiga 50711, Indonesia \\ e-mail: ${ }^{1672016001 @ s t u d e n t . u k s w . e d u, ~}{ }^{2}$ ineke.pakereng@uksw.edu
}

\begin{abstract}
Informasi Artikel Diterima: 06-10-2020 Direvisi: $18-11-2020$ Disetujui: 23-11-2020

Abstrak

Saat ini, pengelolaan dokumen merupakan hal penting yang menentukan kelangsungan sebuah organisasi. Pengarsipan dokumen yang tidak dikelola dengan baik dapat menimbulkan banyak masalah. Selain itu, pembuktian keaslian dokumen merupakan hal yang tidak kalah penting. Pada tahun 2019, tercatat banyaknya kasus pemalsuan dokumen di Indonesia maupun di luar negeri. Sistem Manajemen Validasi Document Security ini dibangun menggunakan framework Laravel dan Bootstrap untuk tampilan web, MySQL untuk database, dan QR Code untuk validasi dokumen. Selain dapat mengelola dan validasi dokumen, sistem ini dilengkapi dengan web service yang dapat diintegrasikan dengan aplikasi lainnya. Dari pembuatan sistem ini diharapkan supaya proses pengelolaan dokumen menjadi lebih baik dan juga pemalsuan dokumen dapat diminimalisir.
\end{abstract}

Kata Kunci: Pengelolaan dokumen, , Sistem Manajemen Validasi, QR Code.

\begin{abstract}
Nowadays, document management is an important thing that determines the continuity of an organization. Poorly managed document archiving can cause many problems. In addition, proving the authenticity of documents is no less important. In 2019, there were many cases of document falsification in Indonesia and abroad. This Document Security Validation Management System was built using the Laravel and Bootstrap framework for web viewing, MySQL for databases, and QR Code for document validation. Apart from being able to manage and validate documents, this system is equipped with a web service that can be integrated with other applications. From the creation of this system, it is hoped that the document management process will be better and document falsification can be minimized.
\end{abstract}

Keywords: Document management, Validation Management System, QR Code.

\section{Pendahuluan}

Saat ini, pengelolaan dokumen merupakan hal penting yang menentukan kelangsungan sebuah organisasi. Banyaknya dokumen dalam suatu organisasi yang tidak dikelola melalui sistem menimbulkan berbagai permasalahan diantaranya adalah kesulitan pencarian dokumen secara spesifik, perbedaan format penamaan dokumen setiap orang, tingginya resiko kerusakan, kehilangan hingga pemalsuan dokumen yang sebagian besar disebabkan tidak adanya pengaman yang mengatur siapa saja yang berhak melihat, mengubah, maupun menggunakan dokumen tersebut.

Pembuktian keaslian sebuah dokumen merupakan hal yang tidak kalah penting. Pencetakan dokumen tempo kini sudah menggunakan kertas sekuriti atau kertas dengan pengaman khusus. Akan tetapi, kertas sekuriti sendiri tidak dapat menjamin keaslian dari isi dokumen tersebut. Percetakan kertas sekuriti yang sama persis atau tersebarnya kertas sekuriti kosong dapat digunakan untuk melakukan tindakan-tindakan illegal. Tercatat ada lebih dari 120 kasus pemalsuan dokumen pada tahun 2019 yang telah diunggah di website Direktori Putusan Mahkamah Agung Republik Indonesia dengan kata pencarian pemalsuan dokumen dan filter register 2019 (Kepaniteraan Mahkamah Agung Republik Indonesia, 2020). Tidak hanya di Indonesia saja, pemalsuan travel document juga banyak terjadi pada perbatasan negara seperti di Tiongkok, Iran, Mesir, dan negara-negara di benua Afrika (Frontex, 2019). $\mathrm{Hal}$ tersebut merupakan masalah yang 
melatarbelakangi pembuatan sistem ini yang dapat mengelola seluruh dokumen beserta pengaman yang dapat meminimalisir tingkat penyalahgunaan dan pemalsuan dokumen yang kerap terjadi.

Salah satu metode yang dapat mempermudah pengelolaan dokumen adalah Quick Response Code (QR Code). QR Code yang diterapkan dalam pembuatan dokumen dapat memuat informasi-informasi yang bersifat statis maupun dinamis. Statis berarti informasi yang ditampilkan berisi teks yang tidak dapat diubah, sedangkan informasi dinamis berisi tautan/link yang menuju ke suatu website pengolahan dokumen. Walaupun dapat memuat informasi dinamis, tetapi QR Code itu sendiri hanya dapat menampilkan rangkaian string tautan yang statis dan hanya dapat mengirimkan data menggunakan metode get. Sehingga diperlukan suatu algoritma untuk mengamankan data dalam tautan di QR Code.

Pada penelitian yang berjudul Implementasi Quick Response (QR) Code pada Aplikasi Validasi Dokumen Menggunakan Perancangan Unified Modeling Language (UML) membahas tentang perancangan aplikasi validasi dokumen menggunakan QR Code yang berisi Uniform Resource Locator (URL) yang mengarah pada data dokumen. Berdasarkan pengujian yang dilakukan, pemalsuan dokumen dapat dihindari dengan menggunakan aplikasi ini dengan syarat tidak ada campur tangan super admin dalam pemalsuan dokumen (Murtadho et al., 2016). Pada penelitian yang berjudul Sistem Verifikasi Sertifikat Menggunakan QR Code Pada Central Event Information membahas tentang implementasi QR Code pada sertifikat yang membuktikan bahwa sistem tersebut dapat diterima oleh user dan QR Code mampu meningkatkan unsur keamanan sertifikat. QR Code yang dipasang pada bagian bawah sertifikat berisikan sebuah link yang akan mengarahkan user ke halaman verifikasi. Di halaman tersebut user akan dapat melihat data dari sertifikat dan dari data tersebut user dapat mencocokan dengan sertifikat fisik yang ada (Febriyanto, Rahardja, Faturahman, \& Lutfiani, 2019). Pada penelitian lainnya yang berjudul Sistem Legalisir Scan ljasah Online Berbasis QR Code dan Watermarking membahas tentang pembuatan aplikasi yang digunakan untuk memberikan perlindungan terhadap ijazah digital menggunakan metode verifikasi QR Code. Pada penelitian ini juga membahas tentang pengelolaan ijazah dan sistem yang dapat memberikan melakukan verifikasi ijazah melalui scan QR Code pada ijazah (Hidayat et al., 2015)

Pada penelitian yang berjudul Sistem Pengarsipan Dokumen Guru dan Pegawai
Menggunakan Metode Mixture Modelling Berbasis Web membahas tentang aplikasi pengelolaan data kearsipan untuk mempermudah proses pengarsipan dokumen di SMK Negeri 1 Blitar. Pada penelitian ini dibahas pentingnya pengelompokan data-data dokumen agar mempermudah user dalam mencari informasi tentang suatu dokumen (Lestanti \& Susana, 2016).

Sistem manajemen validasi document security merupakan sebuah sistem yang memiliki 2 fungsi utama, yaitu untuk memanajemen dokumen dan untuk validasi keaslian dokumen. Menurut Shevade perwujudan dari sistem manajemen document security adalah dapatnya sebuah mengelola dokumen pengguna secara aman atau dapat mengelola data pengguna secara aman. (Shevade \& Maharashtra, 2010). Sistem manajemen document security terdiri dari sebuah repository dokumen yang menyediakan fasilitas untuk menyimpan data file yang mempresentasikan dokumen yang disimpan. Validasi dapat diartikan sebagai pengujian kebenaran atas sesuatu (Badan Pengembangan dan Pembinaan Bahasa, 2020). Sehingga, sistem manajemen validasi document security dapat diartikan sebagai sebuah sistem yang memiliki fungsi untuk menyimpan data atau file dokumen secara aman dan memiliki fungsi untuk mengujikebenaran atau keaslian sebuah dokumen.

QR Code adalah barcode 2 dimensi yang dikembangkan oleh perusahaan Jepang DensoWave pada tahun 1994. QR adalah singkatan dari "Quick Response" yang menunjukan bahwa QR Code dapat dibaca dan dengan kecepatan tinggi. Kelebihan dari QR Code lainnya adalah dapat dibaca oleh kamera smartphone tanpa harus menggunakan device lainnya. Selain itu, QR Code dapat menyimpan berbagai macam bentuk data seperti nomor telepon, suatu text atau pesan, dan juga URL (Rouillard, 2008).

Laravel adalah framework PHP. Framework sendiri dapat diartikan sebagai kumpulan kode program siap pakai dengan aturan penulisan tertentu yang bertujuan untuk memudahkan serta mempercepat pembuatan aplikasi (Parkar et al., 2016). Laravel memiliki sintaksis yang ekspresif dan elegan yang memiliki fungsi-fungsi bawaan untuk mempermudah developer dalam pembuatan aplikasi. Fungsi-fungsi yang dimaksud seperti Bundle, Eloquent ORM, Application Logic, Reverse Routing, Class Auto Loading, dll. Laravel merupakan framework PHP yang paling popular pada tahun 2015-2020. Menurut Pratama kepopuleran framework Laravel dapat dikaitkan dengan kebutuhan industri karena sebagian besar lowongan pekerjaan back-end 
developer mensyaratkan pelamar untuk menguasai laravel (Pratama, 2020). Maka dari itu, kepopuleran framework Laravel dapat diartikan bahwa Laravel merupakan salah satu framework PHP terbaik untuk mengembangkan back-end suatu sistem.

Berdasarkan latar belakang permasalahan tersebut, maka penulis merancang dan mengimplementasikan suatu aplikasi berbasis website menggunakan framework laravel dan QR Code sebagai alat validasi dokumen. Dengan adanya aplikasi ini, diharapkan dapat membantu penyelesaian masalah penyalahgunaan dan pemalsuan dokumen.

\section{Metode Penelitian}

Penelitian ini dilakukan dan diselesaikan melalui 7 tahapan penelitian. Tahapan-tahapan penelitian ini dapat dilihat pada Gambar 1.

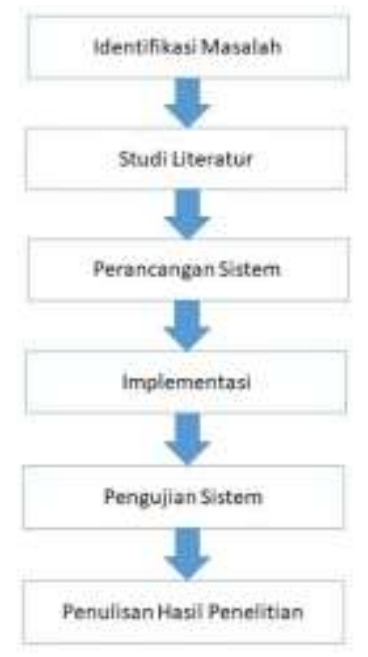

Gambar 1. Metodologi Penelitian

- Identifikasi Masalah

Tahapan pertama yaitu menganalisis kebutuhan dengan cara melakukan pendefinisian masalah. Dalam kasus ini masalah yang ada adalah pengelolaan dan pemalsuan dokumen.

- Studi Litelatur

Tahap kedua adalah studi litelatur. Pada tahap ini dilakukan pembelajaran literatur berupa jurnal ilmiah maupun buku yang menjelaskan mengenai penelitian yang telah dilakukan sebelumnya dan alat-alat yang digunakan sebagai referensi untuk memecahkan masalah mengenai kasus yang ada. Penelitian sebelumnya yang menjadi acuan adalah penelitian tentang sistem pengersipan dan pengamanan dokumen dengan QR Code.

- Perancangan Sistem
Pada tahap ketiga ini dilakukan perancangan sistem menggunakan UML (Unified Modelling Language). Dalam hal ini UML yang dibuat adalah use case diagram, activity diagram, dan class diagram.

- Implementasi Sistem

Pengimplementasian sistem berdasarkan rancangan yang telah dibuat menggunakan framework Laravel sebagai framework utama, framework Bootstrap untuk tampilan, JQuery, dan database MySql,

- Pengujian Sistem

Pada tahap ini penulis menguji sistem yang telah diimplementasi menggunakan data dummy yang menyerupai bentuk data aslinya. Pengujian lainnya menggunakan blackbox testing yang dilakukan untuk memastikan semua fitur berfungsi dan tidak memiliki bug.

- Penulisan Hasil Penelitian

Pada tahap ini dilakukan dokumentasi proses dari tahap awal sampai tahap akhir dalam bentuk tulisan ilmiah.

\section{Hasil dan Pembahasan \\ 1. Perancangan Sistem}

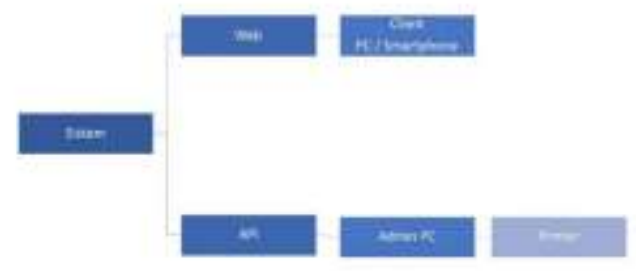

Gambar 2. Diagram Arsitektur Sistem

Gambar 2 merupakan diagram sederhana yang menunjukan arsitektur dari sistem ini. Secara garis besar sistem ini memiliki 2 buah fungsi utama yaitu sebagai web dan sebagai Application Programming Interface atau API. Sebagai web sistem ini dapat dibuka oleh setiap user dan admin. Pada web ini user dapat registrasi, login, melihat dokumen, mengunggah dokumen, dan mengunduh dokumen. Sedangkan sebagai API sistem ini dikhususkan untuk dapat mengambil dokumen dari server. 


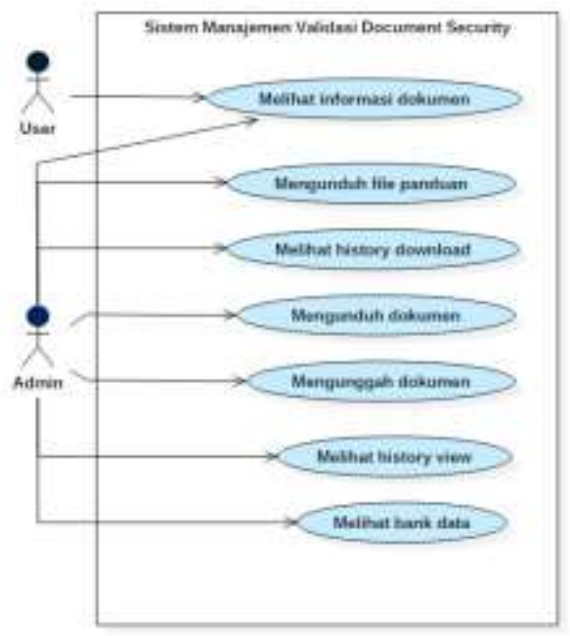

Gambar 3. Use Case Diagram

Dari Gambar 3 dapat diketahui pada sistem ini terdapat dua orang aktor utama yaitu admin dan user. Admin dapat mengelola seluruh data dokumen, mulai dari melihat dokumen, mengunduh file panduan, melihat history download dan history view sedangkan user hanya dapat melihat informasi dokumen.

\section{Activity Diagram}

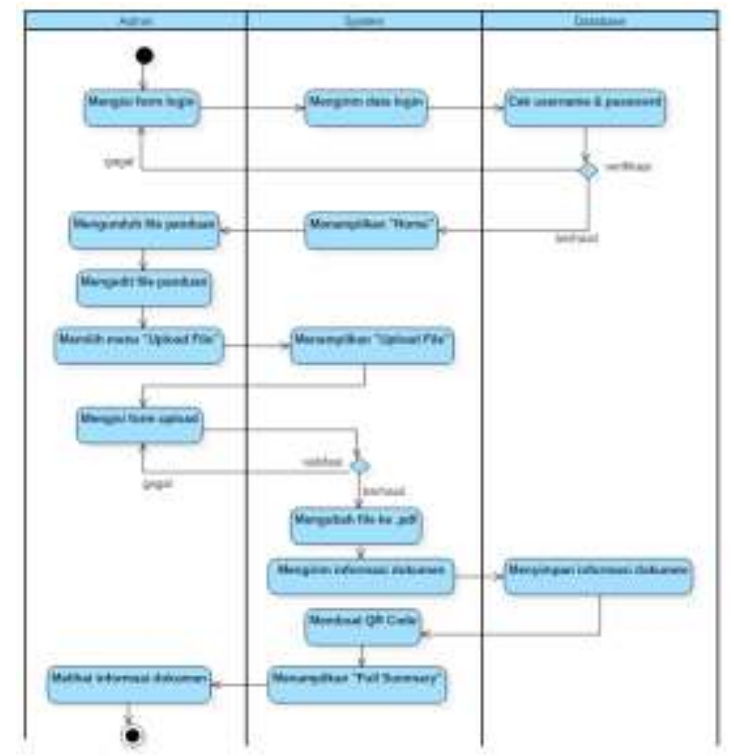

Gambar 4. Activity Diagram Admin

Dari Gambar 4 dapat diketahui alur aktivitas yang dilakukan oleh admin. Pertama, admin diwajibkan untuk mengisi form login yang terdiri dari username dan password, setelah itu sistem akan mengirim data ke database lalu melakukan pengecekan data tersebut dengan data yang telah tersimpan di database. Apabila hasilnya valid, maka sistem menampilkan halaman "Home". Setelah itu, admin dapat mengunduh file panduan dengan menekan tombol download pada menu "File Panduan". Selanjutnya, file yang telah diunduh dapat disesuaikan dengan kebutuhan. Untuk mengunggah dokumen, admin dapat menekan tombol "Upload" pada menu "Upload File" lalu mengunggah file dan mengisi form yang ditampilkan oleh sistem. Selanjutnya sistem akan memvalidasi semua inputan dan mengubah file ke dalam bentuk .pdf. Kemudian sistem mengirim informasi dokumen ke database lalu disimpan. Setelah data dokumen disimpan sistem akan membuat QR Code yang berisikan link ke halaman Full Summary dokumen tersebut. Terkahir, sistem akan mengalihkan halaman browser ke halaman Full Summary tersebut.

Link di dalam QR Code yang dibuat akan berbentuk seperti /document/summary//sha256\}. SHA-256 yang berada diakhir link menunjukan id unik untuk tiap QR Code. Penggunaan SHA-256 dalam link tersebut dimaksudkan agar user lain tidak dapat melihat dokumen lain sebelum user tersebut mendapatkan QR Code untuk dokumen yang diinginkan.

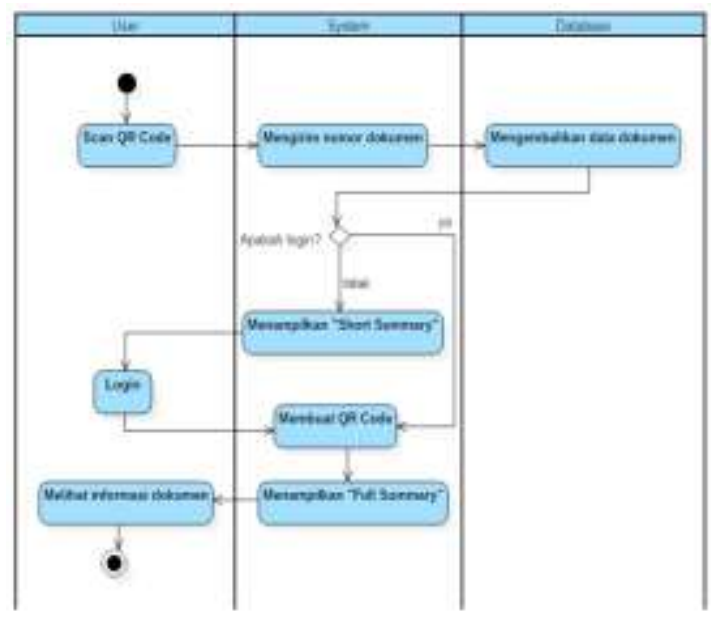

Gambar 5. Activity Diagram User

Dari Gambar 5 menunjukan alur aktivitas yang dilakukan oleh user. Pertama, user dapat melakukan scan pada QR Code yang terdapat pada dokumen lalu membuka link yang disimpan dalam QR Code tersebut. Setelah itu, sistem akan mencari data dokumen sesuai dengan token yang berada di dalam link. Setelah itu, sistem akan mengecek apakah user telah login. Jika user telah login maka sistem akan membuat QR Code dokumen tersebut lalu menampilkan halaman Full Summary. 


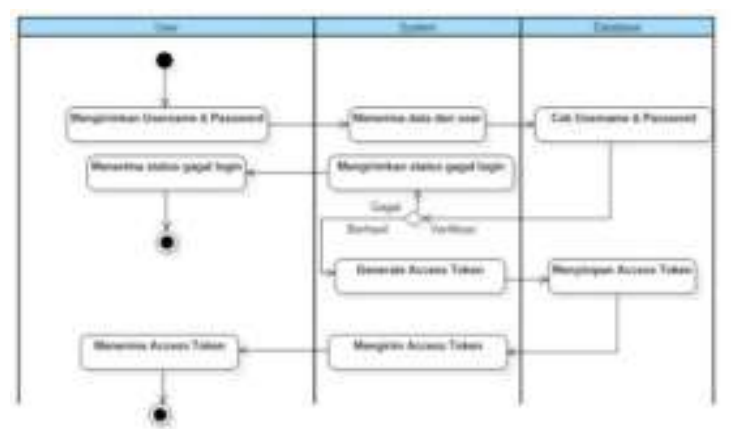

Gambar 6. Activity Diagram API Login

Gambar 6 merupakan activity diagram fungsi login yang terdapat pada API sistem ini. Untuk melakukan login menggunakan API user diminta untuk mengirimkan 2 buah parameter yaitu username dan password. Setelah itu sistem akan melakukan pengecekan kecocokan username dan password tersebut. Jika username dan password tersebut cocok dengan data user di dalam database sistem akan membuat sebuah Access Token yang dapat digunakan oleh user untuk melakukan fungsi API lainnya. Sebaliknya, jika username dan password tidak cocok maka user akan menerima pesan gagal login.

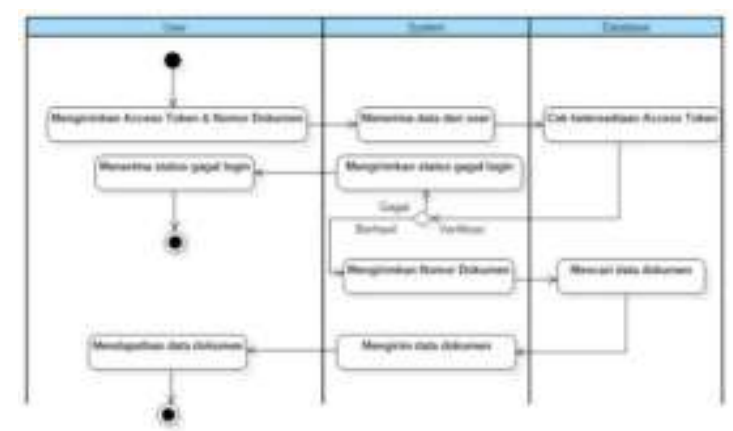

Gambar 7. Activity Diagram Get API Document

Gambar 7 merupakan Activity Diagram fungsi Get Document yang dapat diakses menggunakan API sistem ini. Fungsi ini digunakan untuk mengambil data-data dokumen yang bersesuaian dengan nomor dokumen yang diinputkan. Fungsi Get Document hanya dapat digunakan setelah user melakukan login dan menerima Access Token dari fungsi login sebelumnya. User perlu untuk mengirimkan Access Token dan nomor dokumen diminta. Setelah menerima inputan dari user sistem akan melakukan pengecekan terhadap Access Token yang diberikan oleh user. Jika Access Token sesuai maka sistem akan mencari data dokumen di database sesuai dengan inputan nomor dokumen dari user lalu mengirimkannya kepada user.

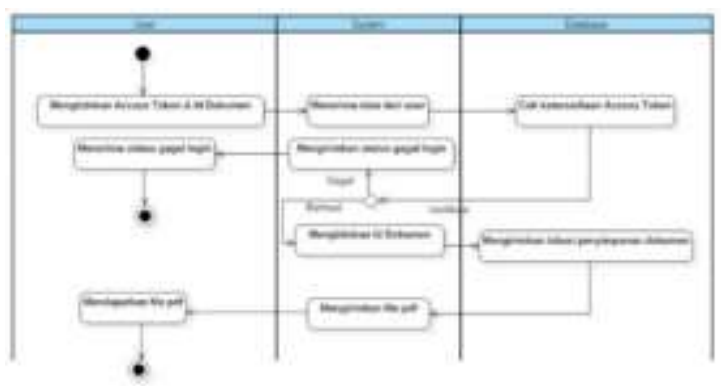

Gambar 8. Activity Diagram API Get File PDF

Gambar 8 merupakan Activity Diagram fungsi Get File PDF yang dapat diakses menggunakan API sistem ini. Sama seperti fungsi Get Document diperlukan Access Token untuk dapat menggunakan fungsi ini. Selain Access Token fungsi ini memerlukan inputan ld Document yang bisa didapatkan dari fungsi Get Document sebelumnya. Fungsi ini akan mengirimkan dokumen berekstensi .pdf dan telah ditambahkan QR Code di dalamnya.

\section{Class Diagram}

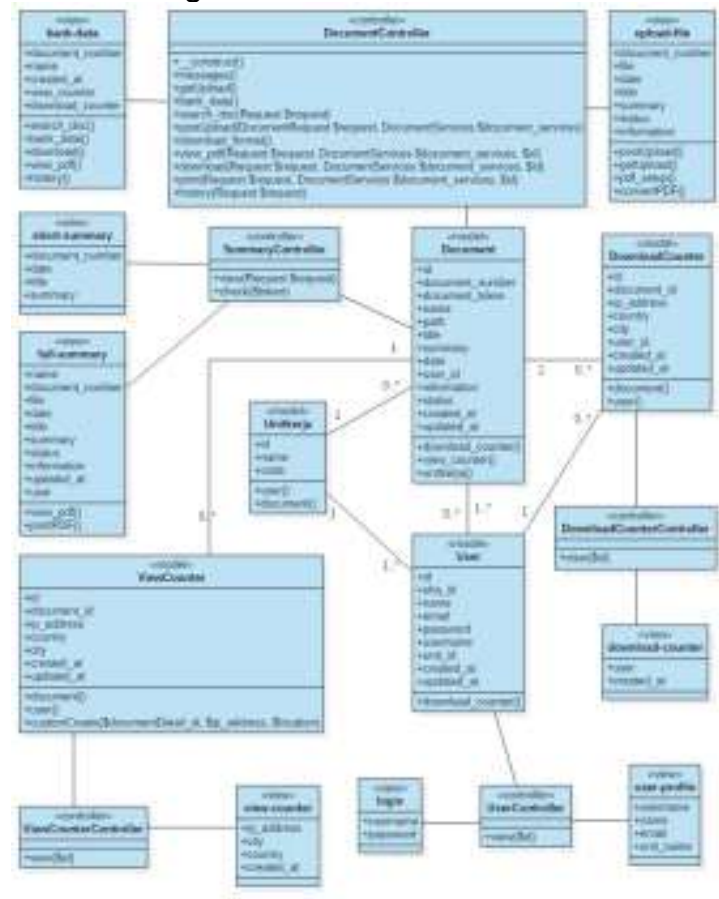

Gambar 9. Class Diagram

Melalui Gambar 9 dapat diketahui bahwa sistem Smart Document ini melibatkan 5 buah model, 8 buah view, dan 5 buah controller.

\section{Implementasi \\ Hasil dari implementasi sistem ini dapat dilihat pada gambar 10-15.}




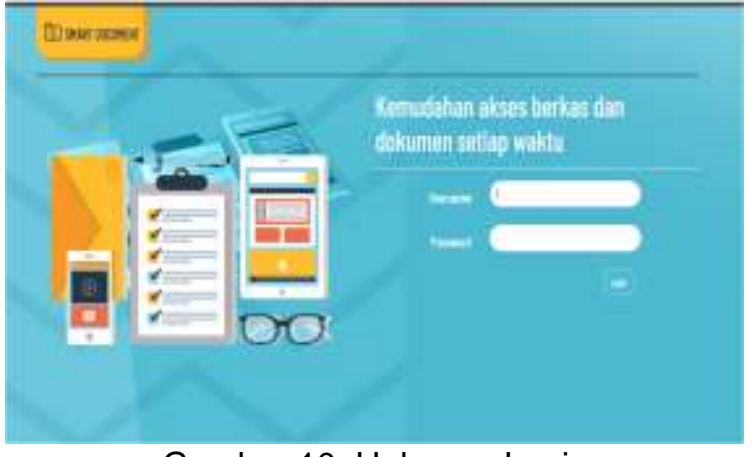

Gambar 10. Halaman Login

Dalam sistem ini terdapat halaman login yang muncul ketika pertama kali membukanya. User diminta untuk memasukkan username dan password.

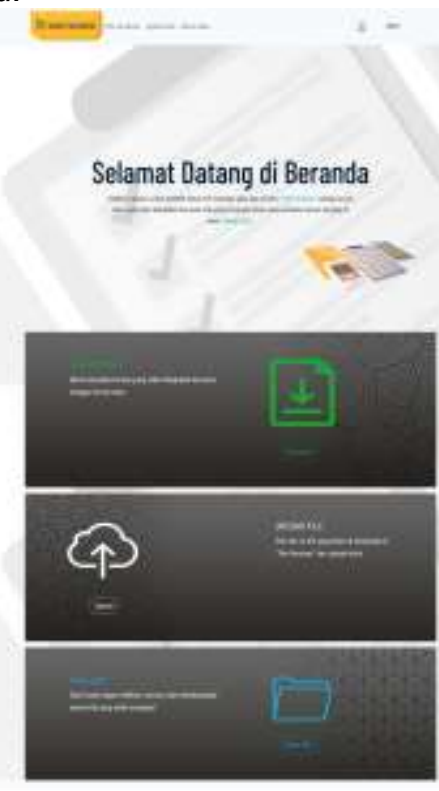

Gambar 11. Halaman Home

Pada Gambar 11 merupakan tampilan home yang akan terbuka apabila user berhasil login. Pada halaman ini, terdapat tombol download yang berfungsi untuk mengunduh file panduan, tombol upload yang menuju ke tampilan unggah dokumen, dan tombol open file yang menuju ke halaman bank data.

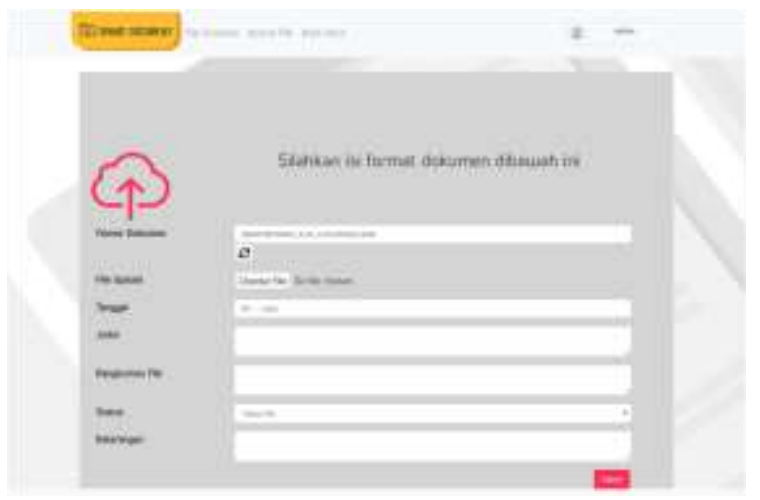

Gambar 12. Halaman Upload Document
Pada halaman Upload File pengguna diminta untuk memasukkan file yang ingin diunggah, tanggal, judul, rangkuman, status file, dan keterangan yang berkaitan dengan dokumen yang akan disimpan.

Isian nomor dokumen bersifat autogenerate, namun user diperbolehkan mengubahnya. Pada isian status, user diperkenankan memilih status file yang terdiri dari "draft", "ahli 1"," ahli 2", "ahli 3", "ahli 4", dan "final". Setelah itu pengguna dapat menekan tombol submit agar file yang diunggah dapat disimpan dan diberi Qr Code sebagai identitas dokumen, apabila proses upload berhasil maka pengguna akan dialihkan ke halaman Full Summary.

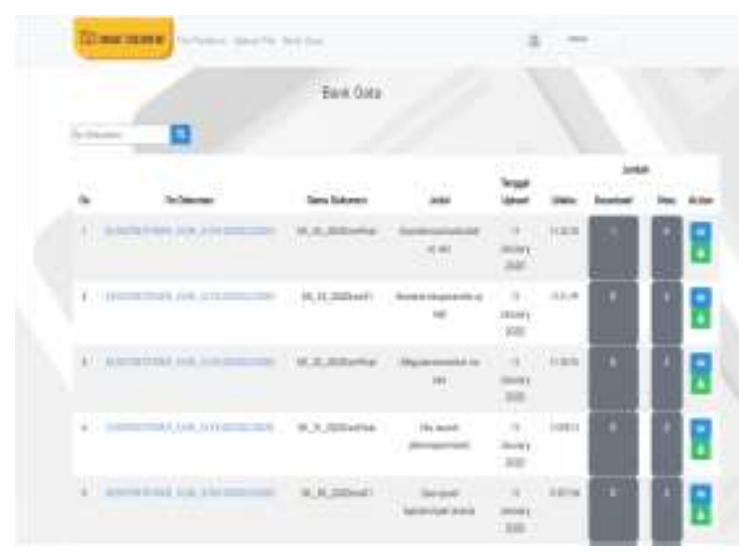

Gambar 13. Halaman Bank Data

Pada halaman ini, user dapat melihat seluruh informasi dokumen yang telah diunggah, diantaranya adalah nomor dokumen, nama dokumen, judul, tanggal dan waktu upload, beserta jumlah download dan view yang dilakukan oleh user. Nomor dokumen ditampilkan sebagai link yang dapat digunakan untuk menuju ke halaman Full Summary yang dapat digunakan untuk mengelola informasi yang lebih rinci berkaitan dengan dokumen yang bersangkutan. Jumlah download dan view ditampilkan sebagai tombol yang dapat digunakan untuk menuju ke halaman history view maupun history download. Melalui halaman ini admin juga dapat langsung melihat maupun mengunduh file asli melalui tombol yang disediakan di dalam kolom action. 


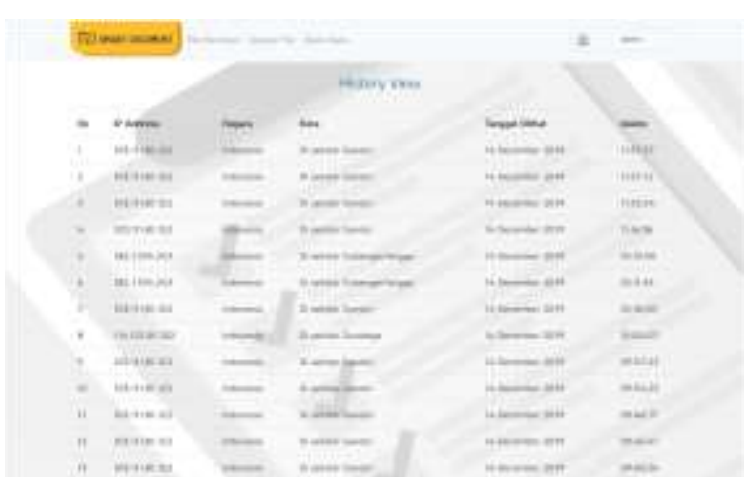

Gambar 14. Halaman History View

Gambar 14 merupakan tampilan halaman history view. Halaman ini menampilkan IP Address, negara, kota, tanggal dan waktu user melihat dokumen yang dipilih.

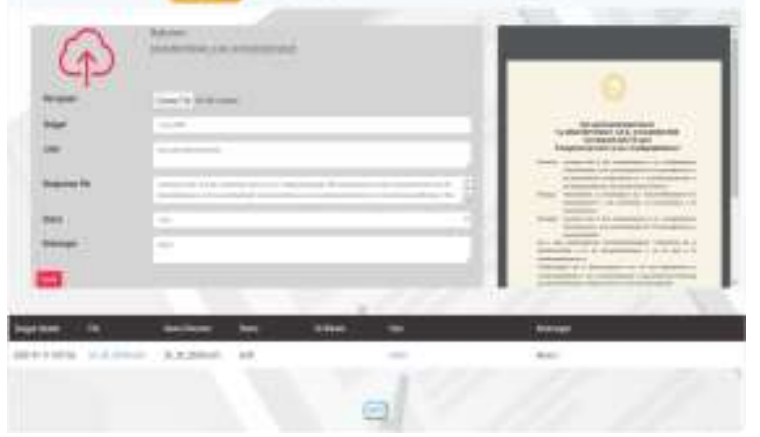

Gambar 15. Halaman Full Summary

Gambar 15 menunjukan halaman Full Summary. Halaman ini adalah halaman yang akan dibuka pada saat user membuka link pada QR Code. Pada halaman ini, user dapat memperbaharui informasi dokumen maupun memasukkan file baru, melihat riwayat update dokumen melalui tabel yang disediakan, dan mencetak dokumen yang terbaru menggunakan tombol print. Nama file ditampilkan sebagai link yang dapat digunakan untuk mengunduh file.

\section{Kesimpulan}

Berdasarkan penelitian yang dilakukan maka dapat disimpulkan bahwa Sistem Manajemen Validasi Document Security yang telah dirancang dan diimplementasikan dengan bahasa pemrograman PHP dan Javascript, framework Laravel, database MySQL serta library jQuery dapat menyimpan dan mengelola dokumen dengan baik. Selain itu, dengan QR Code yang ditempatkan pada dokumen dapat digunakan sebagaik alat untuk pengecekan keaslian dokumen tersebut karena QR Code yang berada di dokumen tersebut dibuat oleh sistem dan berisikan link yang dapat dibuka untuk melihat bentuk dokumen asli yang disimpan oleh sistem. Selain itu, sistem ini memiliki API yang dapat digunakan oleh admin untuk mendapatkan dokumen yang telah diunggah sebelumnya dan mencetak dokumen tersebut.

Adapun saran yang diperlukan untuk mengembangkan sistem ini adalah membuat aplikasi desktop yang menggunakan API sistem ini. Dari aplikasi desktop dapat dihubungkan lagi dengan printer khusus yang hanya bisa mencetak dokumen jika menggunakan aplikasi desktop tersebut sehingga pencetakan isi dokumen dapat terjamin keasliannya.

\section{Referensi}

Badan Pengembangan dan Pembinaan Bahasa. (2020). KBBI Daring. https://kbbi.kemdikbud.go.id/entri/validasi

Febriyanto, E., Rahardja, U., Faturahman, A., \& Lutfiani, N. (2019). Sistem Verifikasi Sertifikat Menggunakan Qrcode pada Central Event Information. Techno.Com, 18(1), 50-63. https://doi.org/10.33633/tc.v18i1.2078

Frontex. (2019). Annual Risk Analysis 2019. https://frontex.europa.eu/assets/Publicatio ns/Risk_Analysis/Risk_Analysis/Risk_Ana lysis_for_2019.pdf

Hidayat, $\overline{\mathrm{E}}$. Y., Firdausillah, F., \& Hastuti, K. (2015). Sistem Legalisir Scan ljasah Online BERBASIS QR CODE DAN WATERMARKING. Techno.COM, 14(1), 13-24.

Kepaniteraan Mahkamah Agung Republik Indonesia. (2020). Direktori Putusan Mahkamah Agung Republik Indonesia. https://putusan3.mahkamahagung.go.id/s earch.html?q=\%22Pemalsuan dokumen\%22\&tp=0\&t_reg $=2019$

Lestanti, S., \& Susana, A. D. (2016). Sistem Pengarsipan Dokumen Guru Dan Pegawai Menggunakan Metode Mixture Modelling Berbasis Web. Antivirus: Jurnal Ilmiah Teknik Informatika, 10(2), 69-77. https://doi.org/10.35457/antivirus.v10i2.16

Murtadho, M., Musthofa, N., \& Mutrofin, S. (2016). Implementasi Quick Response (QR) Code Pada Aplikasi Validasi Dokumen Menggunakan Perancangan Unified Modelling Language (UML). Antivirus : Jurnal IImiah Teknik Informatika, 10(1), 42-50. https://ejournal.unisbablitar.ac.id/index.ph p/antivirus/article/view/87/83

Parkar, V. V, Shinde, P. P., Gadade, S. C., \& Shinde, P. M. (2016). Utilization of Laravel Framework for Development of Web Based Recruitment Tool. IOSR Journal of Computer Engineering (IOSR-JCE), 3641.

Pratama, A. (2020). Laravel Uncover.

Rouillard, J. (2008). Contextual QR codes. Proc. 
- The 3rd Int. Multi-Conf. Computing in the Global Information Technology, ICCGI 2008 in Conjunction with ComP2P 2008: The 1st Int. Workshop on Computational P2P Networks: Theory and Practice. https://doi.org/10.1109/ICCGI.2008.25

Shevade, R., \& Maharashtra. (2010).
DOCUMENT SECURITY MANAGEMENT SYSTEM.

https://patentimages.storage.googleapis.c om/3f/83/75/ede2c0f7928bd1/US2010021 7987A1.pdf 